\title{
Working Memory Interventions With Children: Classrooms or Computers?
}

\author{
Susan Colmar ${ }^{1}$ and Kit Double ${ }^{2}$ \\ 1 Sydney School of Education and Social Work, The University of Sydney, New South Wales, Australia \\ 2 School of Psychology, The University of Sydney, New South Wales, Australia
}

\begin{abstract}
The importance of working memory to classroom functioning and academic outcomes has led to the development of many interventions designed to enhance students' working memory. In this article we briefly review the evidence for the relative effectiveness of classroom and computerised working memory interventions in bringing about measurable and sustainable benefits to students' working memory, classroom engagement, and academic performance. Although there is considerable evidence that working memory is significantly linked to academic achievement, virtually no research has been undertaken within the classroom context, nor has the research had an intervention focus, nor has any research involved students themselves. Although there is a large amount of research on computerised working memory training programs, the evidence confirms that such programs rarely provide transferable or sustainable benefits to students' working memory, classroom functioning, or academic performance. Positive evidence is provided for one classroom intervention specifically designed for personal and independent use by students, with their teachers' support. Recommendations for classroom practice and directions for further research combining classrooms and computer interventions are discussed.
\end{abstract}

Keywords: working memory, interventions, classroom programs, computer programs

In this article we explore working memory interventions for school-aged students using key criteria to evaluate their impact and effectiveness. Initial definitions of working memory and a short overview of some key research findings are provided (e.g., Colmar, Davis, \& Sheldon, 2016; Gathercole \& Alloway, 2007; Klingberg, 2010). We have developed a typology of the three types of currently available working memory interventions to clarify the range and scope of these for the reader. These interventions consist of: (a) guidelines for training teachers, (b) studentspecific strategies provided within the classroom context, and (c) computer-based

ADDRess fOR CORRESPONDENCE: Associate Professor Susan Colmar, Program Director for School Counselling and School Psychology, Sydney School of Education and Social Work, Room 805, Education Building A35, The University of Sydney NSW 2006, Australia. Email: susan.colmar@sydney.edu.au 
training aiming to increase working memory capacity. Further, it can be argued that working memory programs can make a significant impact on:

1. increasing students' working memory capacity;

2. supporting students' use of already known, but possibly infrequently accessed, working memory strategies; and

3. increasing the range of working memory strategies that students might access, thus teaching students new working memory strategies.

Underlying all approaches to enhancing working memory is the premise that there will be positive changes in 'how' and how well students learn; in other words, changes in cognitive processes and observable classroom learning and engagement. Further, it is often assumed, but generally not proven, that this leads to improvements in students' academic performance and progress, or the 'what' of learning.

Our aim is to establish the importance of bringing effective working memory strategies into the classroom context by providing students themselves with accessible attention and working memory strategies, and by training their teachers to facilitate students' use of strategies and students' development of skills to better engage in optimal learning. This approach is in contrast to the popular use of computer-based working memory training programs, such as CogMed (Bergman Nutley \& Söderqvist, 2017), although we conclude that research investigating a combination of these approaches would be of considerable merit and interest.

\section{The Nature and Impact of Working Memory}

Working memory has been recognised as one of the most important cognitive constructs linked to effective teaching and learning to emerge from cognitive psychology (Alloway, Doherty-Sneddon, \& Forbes, 2012; Dehn, 2011). However, it remains difficult to arrive at a single cohesive definition of working memory, with continued development and debate over its meaning and function. Many definitions of working memory characterise it as a cognitive system responsible for the immediate storage and manipulation of information (e.g., Alloway, 2011; Baddeley, 2003). Gathercole describes working memory as 'several interacting subsystems that include specialised stores for verbal and visuo-spatial material, and an attentional component that controls activity within working memory' (2008, p. 382). Although working memory is often presented as a cognitive capacity that has attentional components, it can also be conceptualised as an observable set of skills or strategies used by students to ensure effective cognitive and academic functioning (Davis, Sheldon, \& Colmar, 2014; Gathercole, 2015). A working memory index has featured in both the Wechsler Intelligence Scale for Children - Fourth Edition (WISC-IV) and the new WISC-V, acknowledging the important role of working memory as part of cognitive functioning. Although there are continuing definitional issues and debates about the nature and measurement of working memory (Alloway \& Alloway, 2013; Baddeley, 2003), these are beyond the scope of this article, which focuses on working memory interventions, particularly those that are appropriate for younger students.

The traditional view of working memory development argues that working memory capacity develops throughout childhood and early adulthood, before levelling 
off and eventually declining during adulthood, with evidence that this developmental trajectory is underpinned by naturally occurring neurological changes in brain structures and activation (Casey, Giedd, \& Thomas, 2000). Further, working memory and academic achievement are closely associated, and this association may be reciprocal and bidirectional, with time spent in schooling making a positive impact, such that increases in working memory have been observed within the duration of a school year, independently of age (Roberts et al., 2015).

The development of working memory capacity is thought to be of critical importance to academic outcomes and the development of complex cognitive skills, such as language, literacy, and mathematical ability (DeMarie \& López, 2013). An expanding body of evidence has demonstrated a link between working memory and the performance of specific academic abilities (Aronen, Vuontela, Steenari, Salmi, \& Carlson, 2005; DeMarie \& López, 2013; Gathercole, Pickering, Knight, \& Stegmann, 2004). For instance, one study by Monette, Bigras, and Guay (2011) showed that when children begin school, their working memory predicts their later academic ability over and above pre-existing differences in family, affect and ability variables. Other researchers have shown a positive relationship between working memory capacity and the development of reading and literacy (Normand \& Tannock, 2014; St Clair-Thompson \& Gathercole, 2006) and mathematics (Bull, Espy, \& Wiebe, 2008; Bull \& Scerif, 2001). Importantly, working memory is believed to be of critical importance when learning new information and novel concepts (Pickering, 2006).

Previous research has suggested that poor working memory function is linked to poor academic performance in primary school children (Gathercole \& Pickering, 2000). For example, this includes poor attention as a key necessary element of working memory, and working memory overload when, for example, students cannot manage multiple instructions. It is suggested that about $10 \%$ to $15 \%$ of children in regular classrooms have working memory difficulties and that this negatively impacts on their academic learning and progress (Gathercole \& Alloway, 2008). Given that successful attention, listening to, and following the teachers' instructions are key elements of effective functioning in most classrooms from middle primary school onwards, it is unsurprising that addressing and remediating the effects of working memory problems have become increasingly important concerns for school psychologists and educators (e.g., Minear \& Shah, 2006; St Clair-Thompson \& Gathercole, 2006).

\section{Working Memory Interventions}

Typically, interventions aim to assist children with working memory difficulties by targeting one of three key pathways:

1. Training the teacher to make appropriate adaptations within the classroom context (e.g., Elliot, Gathercole, Alloway, Holmes, \& Kirkwood, 2010);

2. Ensuring the students are provided with personal access to strategies to manage tasks using attention and working memory skills independently within the classroom context (e.g., Colmar et al., 2016; Davis et al., 2014); and 
3. Training working memory capacity directly, typically using a computerised working memory program, with Alloway, Robinson, and Frankenstein (2016) describing narrow-scope and broad-scope training programs, where the former aims to train skills similar to those used in the pre- and post-tests, and the latter trains working memory in the context of broader abilities, including attention and learning skills.

This paper will now briefly and critically review the evidence for the efficacy of working memory interventions both within the classroom and using computerised working memory interventions, particularly with regard to their effectiveness at bringing about measurable benefits to students' academic performance and classroom behaviour and engagement. However, it is first necessary to establish the criteria by which the interventions will be judged, and this is particularly important given that different expectations about what constitutes a successful working memory intervention have complicated the interpretation of intervention studies (Birney, 2015). With regard to working memory interventions, researchers and psychologists are typically interested in three levels of effect, which are:

1. near transfer effects, which are improvements on a similar task to the trained task but using different stimuli or response mode;

2. far transfer effects, which are gains on a task dissimilar to the trained task, such as a measure of fluid intelligence; and

3. improvement in everyday functioning, academic performance and behaviour, which is known as generalisation.

School counsellors, school psychologists, and teachers are particularly interested in the extent to which working memory interventions can improve student outcomes on measures of academic performance, such as standardised tests (e.g., Elliot et al., 2010). For our purposes, we will consider evidence at each level of effect, but regard them hierarchically; that is, transfer to everyday classroom functioning is more persuasive than far transfer, which is in turn more persuasive than near transfer.

\section{Working Memory Interventions in the Classroom}

Logically, given the strong relationship between working memory and academic achievement, classroom-oriented interventions should provide effective conditions for optimal transfer or generalisation, as the context and the students' learning and academic requirements within the classroom are closely related. To date, most classroom-based working memory interventions have focused on training the teacher to support students by providing key adjustments within the classroom. A number of books and articles, summarising key adaptations for children with working memory difficulties, and written for teachers, parents and school psychologists, have been published (Alloway, 2006, 2011; Dehn, 2008; Elliott et al., 2010; Gathercole \& Alloway, 2007, 2008). For example, ensuring initial attentiveness by engaging the whole class, and the simplification of the instructions and their presentation in more than one mode, such as spoken and written, are relevant adaptations that most teachers can easily make. Another key role in training 
teachers to successfully assist students, particularly those with working memory difficulties, is to ensure that teachers are observant of the behavioural indicators of working memory overload. The teacher can then immediately adapt within context and provide additional support, thus ensuring the student does not switch off or become disengaged from the classroom task. DeMarie and López (2013) sum up the teacher's role succinctly when they state that 'instead of teaching students only procedures of what to do, teachers need to spend instructional time helping students to understand how to study, and why using particular strategies will help them to learn different types of material' (p. 858).

Research within classroom contexts has been very limited. Elliott et al. (2010) focused on training teachers how to provide an appropriate classroom environment to support students with working memory difficulties. The intervention period of eight months was implemented across three groups: intervention, control, and academic direct instruction. No differences were found between the groups across several outcome measures, including working memory, reading, and mathematics. Importantly, they noted that the teachers' use of supportive adjustments, independent of group allocation, were effective, suggesting that teacher strategies per se can make a positive difference.

Students may be able to make greater gains in their working memory capacity and use their working memory skills more often and with greater and broader facility by following a specific classroom-integrated intervention program targeted directly at the students, facilitating their independent use of and ownership of the strategies. Recently, Colmar and colleagues (Colmar et al., 2016; Davis et al., 2014; Sheldon, Davis, \& Colmar, 2015) developed a unique classroom-based working memory intervention called Memory Mates that addresses the two classroomoriented approaches simultaneously: (1) training the teacher to become aware of and to provide adjustments to facilitate students' attention and working memory, and (2) providing the students individually with strategies to use independently to manage attention and working memory difficulties.

Memory Mates consists of 10 student-relevant attention and working memory icons, with short explanations derived from the research literature (Davis \& Sheldon, 2013, as cited in Colmar et al., 2016; see Figure 1), and a booklet for teachers outlining how to implement the Memory Mates' strategies as a classroom intervention (Sheldon et al., 2015). Students are taught and supported in using the 10 strategies focused on how to best attend, learn, and engage in classroom activities across all academic areas.

In an initial article involving targeted students within one class, major improvements in engagement were observed, with positive feedback from the teacher, and this research work assisted in the further development of the specific strategies (Davis et al., 2014).

In a small-scale evaluation of the Memory Mates project with two classes in a single school, one functioning as the intervention classroom and one as the control, no significant impact on academic outcomes was noted (Colmar et al., 2016). However, teachers', students' and parents' feedback was very positive, with interesting meta-cognitive insights from students about how they used the strategies at school and home. Further, children particularly enjoyed having a peer memory coach who could assist them when necessary (see Figure 1). The short period of 

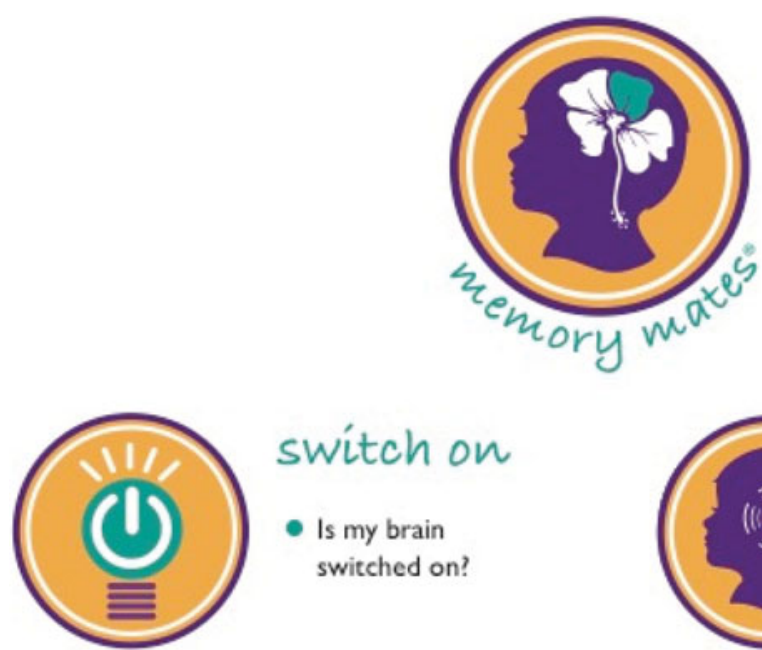

\section{switch on}

- Is my brain switched on?

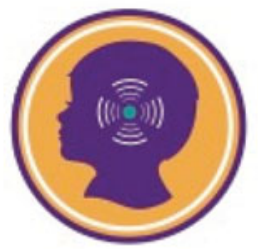

Listen

- Listen to the teacher's instructions

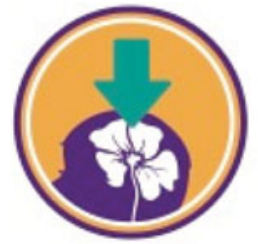

download

- Put the teacher information into my brain

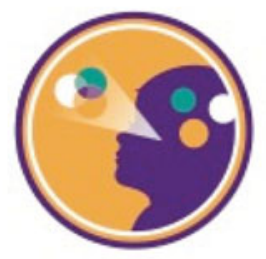

picture it

- Create a picture of the activity in my mind

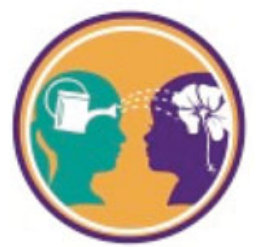

\section{memory} coach

- Talk to my memory coach about the activity

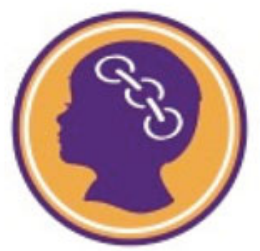

link

- What can I link this to?

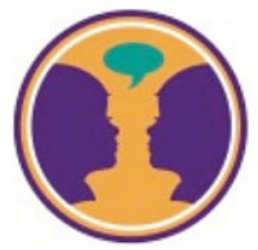

\section{selftalk}

- Say it again to myself

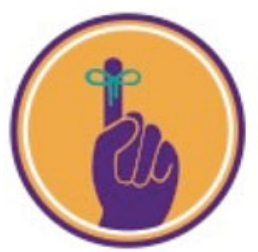

memory aids

- What things can I do to help remember?

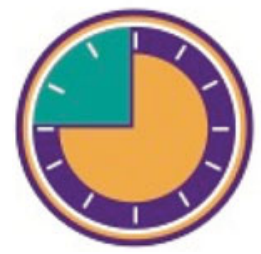

\section{time check}

- How fast am I going?

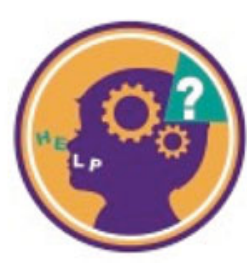

forgotten?

- Look at the board

- Re - read the instructions

- Ask my memory coach

- Ask the teacher for help

\section{FIGURE 1}

(Colour online) Memory Mates icons and explanations. 
intervention, which was 5 weeks, was the most likely reason for the inconclusive findings.

In a comprehensive evaluative study (Colmar et al., 2017), teachers of six classes of Year 4 students implemented Memory Mates for 8 months, with seven classes functioning as a waitlist control group. Results confirmed significant changes in mathematics and spelling in the Memory Mates group compared with no-contact controls. Reading comprehension and academic engagement were not significantly different, although reading engagement increased in both groups over the period of intervention. In addition, students responded well and again showed meta-cognitive insights about their own attention and working memory processes. These significant and interesting findings suggest that directly providing young students with childappropriate strategies is an important and currently under-researched approach.

One of the key issues facing classroom-based working memory interventions is the need to address attention directly, rather than solely targeting working memory. Inattentiveness can be a key indicator of working memory difficulties in the classroom context (Gathercole, Lamont, \& Alloway, 2006), as well as being critical in ensuring a student gains information fully, ready to encode it into working memory. It has been postulated that inattentiveness occurs and persists because students can become overloaded with instructions and information. Therefore, they are unable to cope well with the educational demands of a classroom, or to sustain academic engagement and academic progress (Gathercole \& Alloway, 2007). Further, these students may present with behavioural difficulties and disrupt other students' learning. In the Memory Mates approach, attention is specifically targeted in the first two strategies (see Figure 1).

\section{Computerised Interventions}

To date, most working memory research and training has focused on improving students' working memory capacity outside the classroom, predominantly using computerised programs; for example, Cog Med (Klingberg et al., 2005) and Jungle Memory (Alloway, 2012; Alloway \& Alloway, 2013). Most computerised working memory programs focus on increasing working memory capacity, with an assumption that transfer or generalisation to everyday contexts, including learning in classrooms, will take place. However, while these commercial programs make optimistic claims about their effectiveness, overall support for the efficacy of such programs within the academic literature is more equivocal. It is particularly difficult to reach strong conclusions about these interventions given that they have often been evaluated on atypical populations, where working memory issues are considered central to the child's impairment; in particular, in relation to attention deficit hyperactivity disorder (ADHD; e.g., Chacko et al., 2014; Egeland, Aarlien, \& Saunes, 2013; Gray et al., 2012).

A number of studies have found promising benefits for cognitive abilities as a result of computerised cognitive training. Klingberg et al. (2005) found that children with ADHD who underwent adaptive computerised working memory training experienced significant improvements in working memory, complex reasoning, and response inhibition compared with a control group who completed the same training but in a non-adaptive fashion. Other researchers have found benefits to fluid 
intelligence, which has a well-established role in educational attainment (Deary, Strand, Smith, \& Fernandes, 2007). For example, Jaeggi, Buschkuehl, Jonides, and Shah (2011) found that children who improved on a computer-game-like working memory task showed benefits to untrained measures of fluid intelligence. Similarly, Bergman Nutley et al. (2011) found that compared to a non-adaptive control condition, children trained on a non-verbal reasoning task significantly improved on measures of fluid intelligence. In the same study, children trained in working memory made improvements in working memory tasks, but with no impact on fluid intelligence.

Ultimately, school psychologists, school counsellors, and educators are most interested in programs that can demonstrate direct benefits to academic outcomes, and number of studies have shown significant benefits of computerised training to academic performance (Dahlin, 2011; Kroesbergen, van't Noordende, \& Kolkman, 2014). Holmes, Gathercole, and Dunning (2009) reported that children with working memory difficulties, who were trained on a range of adaptive working memory tasks for 20 days, showed significant gains on a standardised test of mathematics at a 6-month follow-up; however, given that the control groups were not retested, it is difficult to separate this effect from natural development. In addition, there is some evidence that cognitive training benefits reading processes in children (Loosli, Buschkuehl, Perrig, \& Jaeggi, 2011), including children with special needs (Dahlin, 2011). For instance, Loosli et al. (2011) found that when compared to a matched no-contact control group, a working memory training group showed significant improvements in text and word reading.

Other research studies have reached less optimistic findings with regard to training outcomes. A number of studies have demonstrated that working memory training was able to lead to improvements in memory (or at least scores on cognitive task designed to measure memory), but frequently these gains fail to generalise to academic outcomes (Banales, Kohnen, \& McArthur, 2015; Chacko et al., 2014; Henry, Messer, \& Nash, 2013; van der Donk, Hiemstra-Beernink, Tjeenk-Kalff, Van Der Leij, \& Lindauer, 2015). For instance, Dunning, Holmes, and Gathercole (2013) compared improvements in a group of low working memory children trained on an adaptive working memory task ${ }^{1}$ with a group trained on a nonadaptive task. They found that adaptive training led to selective improvements on untrained working memory tasks; however, classroom and academic tasks did not improve relative to non-adaptive difficulty controls, concluding that 'gains do not translate into capacity improvements on ecologically valid measures of working memory or to gains in academic progress' (p. 923). A recent large-scale Australian study following up the impact of CogMed after 2 years, examining the maintenance of near transfer effect and generalisation to academic outcomes, found it had no sustainability or academic impact (Roberts et al., 2016). Further, in a cost benefit analysis, these researchers concluded that CogMed was also expensive and time consuming, with a concomitant loss in classroom learning time.

Meta-analyses confirm that while there may be studies that have found transfer effects of working memory training, overall these effects tend to be short-lived and rarely generalise to academic abilities. A number of reviews have reached sceptical conclusions about the effectiveness of cognitive training (Melby-Lervag \& Hulme, 2013; Shipstead, Redick, \& Engle, 2012). For example, a recent meta-analysis 
examining working memory intervention research completed with children diagnosed with ADHD concluded that the studies were often methodologically poor and most showed little impact on behavioural, cognitive, or academic skills (Rapport, Orban, Kofler, \& Friedman, 2013). Similarly, in their review of the literature, Melby-Lervåg and Hulme (2013) concluded that there is currently no evidence that the benefits of computerised working memory training generalise to other skills or are maintained over the long term. However, it should be noted that interpreting these studies is difficult, as currently much of the research into the effectiveness of working memory training has been carried out on atypical groups of students (in particular, ADHD samples), and the extent to which these findings generalise to normally functioning children is unclear. It is also difficult to interpret many meta-analytical reviews of the literature, as there is often a large degree of heterogeneity in the studies being analysed, particularly in terms of their sample characteristics, the cognitive ability being trained and the training task.

The inconsistent findings reviewed above make it difficult to draw definitive conclusions about the effectiveness of computerised working memory training for children. The contradictory evidence can be explained by a number of factors, including differences in the tools used to measure working memory, the research methodology used, and the theoretical approach taken to training (Birney, 2015; Lampit, Hallock, \& Valenzuela, 2014; Morrison \& Chein, 2011). In particular, Morrison and Chein (2011) draw a distinction between strategy and capacity or core training, and they also note that evaluating the success of a computerised program is highly dependent on the researchers' definitional and conceptual stance, the areas of working memory that they target, and their outcome measures. They further suggest that strategy training may impact on working memory capacity even if temporarily (see also Witt, 2011).

One issue that cognitive training programs face is developing training regimes that are both engaging and effective, which is particularly important for children. Specifically designed cognitive training programs have typically been developed based on redesigns of traditional cognitive assessments (e.g., Stroop test, n-back). While it has been assumed that these activities are the most effective ways to improve cognitive abilities (or at least scores on measures of cognitive abilities), they are not typically engaging over longer sessions or repeated plays (Deveau, Jaeggi, Zordan, Phung, \& Seitz, 2014). Specifically, computerised training is autonomous in nature; it is usually completed at a learner's own pace, often in their home and at the learner's discretion. Learning within such a context is therefore likely to require effective self-regulation on behalf of the learner (Sitzmann \& Ely, 2011) in order for them to train regularly and engage with the training task. However, as working memory is highly involved in self-regulation (Hofmann, Friese, Schmeichel, \& Baddeley, 2011), children who have working memory difficulties are more likely to struggle with the independent and autonomous nature of computerised training.

\section{Recommendations for Practice and Future Research}

This article has reviewed the current evidence base for a number of interventions for children with working memory difficulties. Although we have separated these interventions into classroom-based and computer-based, this should be regarded more 
as a convenient division for looking at working memory interventions, particularly within the current literature, rather than a static dichotomy. However, importantly, despite the publication of a number of books and articles about working memory in children and adolescents, very limited research has focused on training teachers to support students with working memory difficulties. The single exception is Elliot et al. (2010). Further, only one team (Colmar, Davis, and Sheldon's work on Memory Mates; Colmar et al., 2016; Davis et al., 2014; Sheldon et al., 2015) has focused on developing independent attention and working memory strategies and skills in the students themselves. Many students experience difficulties within classrooms, both cognitive and academic, with a negative impact on their wellbeing. Working with teachers and providing strategies to students to enhance and support classroom learning, through attention and working memory strategies, is a key role that school psychologists and counsellors ideally need to know about and to engage with.

To the authors' knowledge there have been no intervention studies that have evaluated the extent to which classroom and computerised interventions could complement one another when used together, particularly in their impact on working memory capacity, the use of, and the frequency of use of a variety of working memory strategies, and academic performance. Future research could explore the differential outcomes of using computerised and classroom interventions together, compared with just one form of intervention.

Children appear to learn better strategies for utilising their attention and working memory more effectively as they get older, and as they adapt to increasing academic demands (Gathercole, 2008; Witt, 2011). A program such as Memory Mates aims to enhance this developmental progression in functionally relevant contexts by targeting students' attention and working memory within the classroom context (Colmar et al., 2016; Davis et al., 2014), and with teacher training and support (Sheldon et al., 2015). Memory Mates aims to increase students' use of a greater variety of working memory skills, the frequency of use of newly learned and existing skills, and students' working memory capacity.

Overall, it is recommended that school psychologists and counsellors support educators to take a multilayered approach by creating a classroom environment that minimises working memory demands and facilitates developing attention and working memory strategies in students, with teacher support. Importantly, students need to be provided concurrently with working memory strategies, such as those presented in the Memory Mates program, that they can use independently, and thus develop and self-regulate their own working memory skills and capacity.

\section{Endnote}

1 Adaptive training refers to training tasks where the difficulty of the tasks adapt to the performance of the trainee, by becoming more difficult as the trainee improves or easier if the trainee is performing poorly. Adaptive tasks are the most widely used form of computerised training and are regarded as more effective than their non-adaptive counterparts.

\section{References}

Alloway, T. (2012). Can interactive working memory training improve learning? Journal of Interactive Learning Research, 23, 197-207. 
Alloway, T.P. (2006). How does working memory work in the classroom? Educational Research and Reviews, 1, 134-139.

Alloway, T.P. (2011). Improving working memory. Supporting students' learning. London, England: Sage Publications.

Alloway, T.P., \& Alloway, R.G. (2013). Working memory: The connected intelligence. New York, NY: Psychology Press.

Alloway, T.P., Doherty-Sneddon, G., \& Forbes, L. (2012). Teachers' perceptions of classroom behaviour and working memory. Education Research and Reviews, 7, 138-142.

Alloway, T.P., Robinson, T., \& Frankenstein, A.N. (2016). Educational application of working-memory training. In T. Strobach \& J. Karbach (Eds.), Cognitive training: An overview of features and applications (pp. 167-175). New York, NY: Springer.

Aronen, E.T., Vuontela, V., Steenari, M.-R., Salmi, J., \& Carlson, S. (2005). Working memory, psychiatric symptoms, and academic performance at school. Neurobiology of Learning and Memory, 83, 33-42.

Baddeley, A. (2003). Working memory: Looking back and looking forward. Nature Reviews: Neuroscience, 4, 829-839.

Banales, E., Kohnen, S., \& McArthur, G. (2015). Can verbal working memory training improve reading? Cognitive Neuropsychology, 32, 104-132. doi:10.1080/02643294.2015.1014331

Bergman Nutley, S., \& Söderqvist, S. (2017). How is working memory training likely to influence academic performance? Current evidence and methodological considerations. Frontiers in Psychology, 8, e69. doi:10.3389/fpsyg.2017.00069

Bergman Nutley, S., Söderqvist, S., Bryde, S., Thorell, L.B., Humphreys, K., \& Klingberg, T. (2011). Gains in fluid intelligence after training non-verbal reasoning in 4-year-old children: A controlled, randomized study. Developmental Science, 14, 591-601.

Birney, D.P. (2015). Challenges for an interdisciplinary consideration of cognitive training. New Directions for Child and Adolescent Development, 147, 21-32.

Bull, R., Espy, K.A., \& Wiebe, S.A. (2008). Short-term memory, working memory, and executive functioning in preschoolers: Longitudinal predictors of mathematical achievement at age 7 years. Developmental Neuropsychology, 33, 205-228. doi:10.1080/87565640801982312

Bull, R., \& Scerif, G. (2001). Executive functioning as a predictor of children's mathematics ability: Inhibition, switching, and working memory. Developmental Neuropsychology, 19, 273-293. doi:10.1207/S15326942DN1903_3

Casey, B.J., Giedd, J.N., \& Thomas, K.M. (2000). Structural and functional brain development and its relation to cognitive development. Biological Psychology, 54, 241-257. doi:http://dx.doi.org/10.1016/S0301-0511(00)00058-2

Chacko, A., Bedard, A., Marks, D., Feirsen, N., Uderman, J., Chimiklis, A., ... Zwilling, A. (2014). A randomized clinical trial of Cogmed working memory training in school-age children with ADHD: A replication in a diverse sample using a control condition. Journal of Child Psychology and Psychiatry, 55, 247-255.

Colmar, S., Davis, N., \& Sheldon, L. (2016). A pilot classroom-based study of attention and working memory strategies for primary aged students. Journal of Psychologists and Counsellors in Schools, 26, 1-12. doi:10.1017/jgc.2016.10 
Colmar, S., Double, K., Davis, N., Sheldon, L., Phillips, N., Cheng, M., \& Briddon, S. (2017). Memory Mates: An evaluation of a classroom-based, student-focused working memory intervention. Manuscript submitted for publication.

Dahlin, K.E. (2011). Effects of working memory training on reading in children with special needs. Reading and Writing, 24, 479-491. doi:10.1007/s11145-010-9238-y

Davis, N., Sheldon, L., \& Colmar, S. (2014). Memory Mates: A classroom-based intervention to improve attention and working memory. Australian Journal of Guidance and Counselling, 24, 111-120.

Deary, I.J., Strand, S., Smith, P., \& Fernandes, C. (2007). Intelligence and educational achievement. Intelligence, 35, 13-21.

Dehn, M.J. (2008). Working memory and academic learning: Assessment and intervention. Hoboken, NJ: John Wiley \& Sons.

Dehn, M.J. (2011). Helping students remember: Exercises and strategies to strengthen memory. Hoboken, NJ: John Wiley \& Sons.

DeMarie, D., \& López, L.M. (2013). Memory in schools. In P.J. Bauer \& R. Fivush (Eds.), The Wiley handbook on the development of children's memory (vol. II, pp. 836-864). Chichester, England: John Wiley \& Sons Ltd.

Deveau, J., Jaeggi, S.M., Zordan, V., Phung, C., \& Seitz, A.R. (2014). How to build better memory training games. Frontiers in Systems Neuroscience, 8, 1-7.

Dunning, D.L., Holmes, J., \& Gathercole, S.E. (2013). Does working memory training lead to generalized improvements in children with low working memory? A randomized controlled trial. Developmental Science, 16, 915-925. doi:10.1111/desc. 12068

Egeland, J., Aarlien, A.K., \& Saunes, B.-K. (2013). Few effects of far transfer of working memory training in ADHD: A randomized controlled trial. PLoS ONE, 8, e75660.

Elliott, J.G., Gathercole, S.E., Alloway, T.P., Holmes, J., \& Kirkwood, H. (2010). An evaluation of a classroom-based intervention to help overcome working memory difficulties and improve long-term academic achievement. Journal of Cognitive Education and Psychology, 9, 227-250.

Gathercole, S.E. (2008). Working memory in the classroom. The Psychologist, 21, 382-385.

Gathercole, S.E. (2015). Understanding and overcoming working memory problems in the classroom. Paper presented at the Pearson Academy Workshop, Sydney.

Gathercole, S.E., \& Alloway, T.P. (2007). Understanding working memory: A classroom guide. London, England: Harcourt Assessment.

Gathercole, S.E., \& Alloway, T.P. (2008). Working memory \& learning. A practical guide for teachers. London, England: Sage Publications.

Gathercole, S.E., Lamont, E., \& Alloway, T.P. (2006). Working memory in the classroom. In S.J. Pickering (Ed.), Working memory and education (pp. 219-240). London, England: Elsevier Press.

Gathercole, S.E., \& Pickering, S.J. (2000). Working memory deficits in children with low achievements in the national curriculum at 7 years of age. British Journal of Educational Psychology, 70, 177-194.

Gathercole, S.E., Pickering, S.J., Knight, C., \& Stegmann, Z. (2004). Working memory skills and educational attainment: Evidence from national curriculum assessments at 7 and 14 years of age. Applied Cognitive Psychology, 18, 1-16. 
Gray, S., Chaban, P., Martinussen, R., Goldberg, R., Gotlieb, H., Kronitz, R., ... Tannock, R. (2012). Effects of a computerised working memory training program on working memory, attention, and academics in adolescents with severe LD and comorbid ADHD: a randomized controlled trial. Journal of Child Psychology and Psychiatry, 53, 1277-1284. doi:10.1111/j.1469-7610.2012.02592.x

Henry, L.A., Messer, D.J., \& Nash, G. (2013). Testing for near and far transfer effects with a short, face-to-face adaptive working memory training intervention in typical children. Infant and Child Development, 23, 84-103. doi:10.1002/icd.1816

Hofmann, W., Friese, M., Schmeichel, B.J., \& Baddeley, A.D. (2011). Working memory and self-regulation. In Kathleen D. Vohs \& R.F. Baumeiste (Eds.), The handbook of self-regulation: Research, theory, and applications (2nd ed., vol. 2, pp. 204-226). New York, NY: Guilford Press.

Holmes, J., Gathercole, S.E., \& Dunning, D.L. (2009). Adaptive training leads to sustained enhancement of poor working memory in children. Developmental Science, 12, F9-F15.

Jaeggi, S.M., Buschkuehl, M., Jonides, J., \& Shah, P. (2011). Short- and long-term benefits of cognitive training. PNAS Proceedings of the National Academy of Sciences of the United States of America, 108, 10081-10086.

Klingberg, T. (2010). Training and plasticity of working memory. Trends in Cognitive Sciences, 14, 317-324.

Klingberg, T., Fernell, E., Olesen, P.J., Johnson, M., Gustafsson, P., Dahlstrom, K., ... Westerberg, H. (2005). Computerised training of working memory in children with ADHD - A randomized, controlled trial. Journal of the American Academy of Child \& Adolescent Psychiatry, 44, 177-186.

Kroesbergen, E.H., van 't Noordende, J.E., \& Kolkman, M.E. (2014). Training working memory in kindergarten children: Effects on working memory and early numeracy. Child Neuropsychology, 20, 23-37. doi:10.1080/09297049.2012.736483

Lampit, A., Hallock, H., \& Valenzuela, M. (2014). Computerised cognitive training in cognitively healthy older adults: A systematic review and meta-analysis of effect modifiers. PLoS Medicine, 11, e1001756.

Loosli, S., Buschkuehl, M., Perrig, W.J., \& Jaeggi, S.M. (2011). Working memory training improves reading processes in typically developing children. Child Neuropsychology, 18, 62-78. doi:10.1080/09297049.2011.575772

Melby-Lervag, M., \& Hulme, C. (2013). Is working memory training effective? A meta-analytic review. Developmental Psychology, 49, 270-291.

Minear, M., \& Shah, P. (2006). Sources of working memory deficits in children and possibilities for remediation. In S.J. Pickering (Ed.), Working memory and education (pp. 273-307). London, England: Elsevier Press.

Monette, S., Bigras, M., \& Guay, M.-C. (2011). The role of the executive functions in school achievement at the end of Grade 1. Journal of Experimental Child Psychology, 109, 158-173.

Morrison, A.B., \& Chein, J.M. (2011). Does working memory training work? The promise and challenges of enhancing cognition by training working memory. Psychonomic Bulletin \& Review, 18, 46-60.

Normand, S., \& Tannock, R. (2014). Screening for working memory deficits in the classroom: The psychometric properties of the working memory rating scale in a longitudinal school-based study. Journal of Attention Disorders, 18, 294-304. doi:10.1177/1087054712445062 
Pickering, S.J. (2006). Working memory in dyslexia. In T.P. Alloway \& S.E. Gathercole (Eds.), Working memory and neurodevelopmental disorders (pp. 7-40). New York, NY: Psychology Press.

Rapport, M.D., Orban, S.A., Kofler, M.J., \& Friedman, L.M. (2013). Do programs designed to train working memory, other executive functions, and attention benefit children with ADHD? A meta-analytic review of cognitive, academic, and behavioral outcomes. Clinical Psychology Review, 33, 1237-1252. doi:http://dx.doi.org/10.1016/j.cpr.2013.08.005

Roberts, G., Quach, J., Mensah, F., Gathercole, S.E., Gold, L., Anderson, P., ... Wake, M. (2015). Schooling duration rather than chronological age predicts working memory between 6 and 7 years: Memory Maestros study. Journal of Developmental and Behavioral Pediatrics, 36, 68-74. doi:10.1097/DBP.0000000000000121

Roberts, G., Quach, J., Spencer-Smith, M., Anderson, P.J., Gathercole, S., Gold, L., ... Wake, M. (2016). Academic outcomes 2 years after working memory training for children with low working memory. JAMA Pediatrics, 170, e154568. doi:doi:10.1001/jamapediatrics.2015.4568

Sheldon, L., Davis, N., \& Colmar, S. (2015). Memory Mates: A classroom-based intervention to improve attention and working memory in primary-aged students. Sydney, Australia: Authors.

Shipstead, Z., Redick, T.S., \& Engle, R.W. (2012). Is working memory training effective? Psychological Bulletin, 138, 628-654.

Sitzmann, T., \& Ely, K. (2011). A meta-analysis of self-regulated learning in workrelated training and educational attainment: What we know and where we need to go. Psychological Bulletin, 137, 421-442. doi: 10.1037/a0022777

St Clair-Thompson, H.L., \& Gathercole, S.E. (2006). Executive functions and achievements in school: Shifting, updating, inhibition, and working memory. The Quarterly Journal of Experimental Psychology, 59, 745-759. doi: 10.1080/17470210500162854

van der Donk, M., Hiemstra-Beernink, A.-C., Tjeenk-Kalff, A., Van Der Leij, A., \& Lindauer, R. (2015). Cognitive training for children with ADHD: A randomized controlled trial of CogMed working memory training and 'paying attention in class'. Frontiers in Psychology, 6, 1-13. doi:10.3389/fpsyg.2015.01081

Witt, M. (2011). School based working memory training: Preliminary finding of improvement in children's mathematical performance. Advances in Cognitive Psychology, 7, 7-15. 